Clinical Research Paper

\title{
Imatinib in systemic mastocytosis: a phase IV clinical trial in patients lacking exon 17 KIT mutations and review of the literature
}

\author{
Iván Alvarez-Twose ${ }^{1,5}$, Almudena Matito, ${ }^{1,5}$, José Mário Morgado ${ }^{1,5}$, Laura Sánchez- \\ Muñoz $^{1,5}$, María Jara-Acevedo ${ }^{2,5}$, Andrés García-Montero ${ }^{2,5}$, Andrea Mayado ${ }^{2,5}$, \\ Carolina Caldas ${ }^{2,5}$, Cristina Teodósio ${ }^{3}$, Javier Ignacio Muñoz-González ${ }^{2,5}$, Manuela \\ Mollejo $^{4,5}$, Luis Escribano ${ }^{2,5}$ and Alberto Orfao ${ }^{2,5}$ \\ ${ }^{1}$ Instituto de Estudios de Mastocitosis de Castilla La Mancha (CLMast), Hospital Virgen del Valle, Toledo, Spain \\ ${ }^{2}$ Centro de Investigación del Cáncer/IBMCC (USAL/CSIC) and IBSAL, Departamento de Medicina and Servicio General de \\ Citometría, University of Salamanca, Salamanca, Spain \\ ${ }^{3}$ Department of Immunology, Erasmus Medical Center, University of Rotterdam, Rotterdam, The Netherlands \\ ${ }^{4}$ Department of Pathology, Hospital Virgen de la Salud, Toledo, Spain \\ ${ }^{5}$ Spanish Network on Mastocytosis (REMA), Toledo and Salamanca, Spain
}

Correspondence to: Iván Alvarez-Twose, email: ivana@sescam.jccm.es

Keywords: mast cell, mastocytosis, well-differentiated systemic mastocytosis, imatinib, KIT

Received: March 01, $2016 \quad$ Accepted: May 29, $2016 \quad$ Published: July 19, 2016

Copyright: Alvarez-Twose et al. This is an open-access article distributed under the terms of the Creative Commons Attribution License 3.0 (CC BY 3.0), which permits unrestricted use, distribution, and reproduction in any medium, provided the original author and source are credited.

\section{ABSTRACT}

Resistance to imatinib has been recurrently reported in systemic mastocytosis (SM) carrying exon 17 KIT mutations. We evaluated the efficacy and safety of imatinib therapy in 10 adult SM patients lacking exon 17 KIT mutations, 9 of which fulfilled criteria for well-differentiated SM (WDSM). The World Health Organization 2008 disease categories among WDSM patients were mast cell $(M C)$ leukemia $(n=3)$, indolent SM $(n=3)$ and cutaneous mastocytosis $(n=3)$; the remainder case had SM associated with a clonal haematological non-MC disease. Patients were given imatinib for 12 months -400 or $\mathbf{3 0 0} \mathrm{mg}$ daily depending on the presence vs. absence of $>30 \%$ bone marrow (BM) MCs and/or signs of advanced disease-. Absence of exon $17 \mathrm{KIT}$ mutations was confirmed in highly-purified BM MCs by peptide nucleic acid-mediated PCR, while mutations involving other exons were investigated by direct sequencing of purified BM MC DNA. Complete response (CR) was defined as resolution of BM $M C$ infiltration, skin lesions, organomegalies and MC-mediator release-associated symptoms, plus normalization of serum tryptase. Criteria for partial response (PR) included $\geq 50 \%$ reduction in BM MC infiltration and improvement of skin lesions and/or organomegalies. Treatment was well-tolerated with an overall response rate of $\mathbf{5 0 \%}$, including early and sustained CR in four patients, three of whom had extracellular mutations of $K I T$, and PR in one case. This later patient and all nonresponders $(n=5)$ showed wild-type $K I T$. These results together with previous data from the literature support the relevance of the KIT mutational status in selecting SM patients who are candidates for imatinib therapy.

\section{INTRODUCTION}

Mastocytosis is a rare and heterogeneous disease characterized by an expansion of clonal mast cells (MCs) in different organs and tissues such as the bone marrow $(\mathrm{BM})$, skin, gastrointestinal tract, liver, spleen and lymph nodes. Based on the World Health Organization (WHO) 2008 classification, mastocytosis is subclassified into several categories including cutaneous mastocytosis $(\mathrm{CM})$, and systemic mastocytosis (SM). SM is further subdivided into indolent SM (ISM), aggressive SM (ASM), SM associated with a clonal haematological 
non-MC disease (SM-AHNMD), MC leukemia (MCL), $\mathrm{MC}$ sarcoma and a provisional subvariant of ISM termed smoldering SM (SSM) [1]. Most SM patients ( 94\%) show morphologically abnormal $\mathrm{CD} 25^{+} \mathrm{BM}$ MCs $[2,3]$ that carry KIT mutations [4-7], from which the KIT $\mathrm{D} 816 \mathrm{~V}$ is the most common one ( $\sim 90 \%$ of SM cases) [6]. The later mutation involves the tyrosine kinase (TK) 2 domain of KIT and leads to constitutive ligandindependent activation of the KIT receptor [8]. Other mutations involving either exon 17 or other exons of KIT (e.g. exons 8, 9, 10 and 11), or a wild-type KIT receptor can be detected in a small percentage of SM patients $(\sim 3 \%$ and $\sim 6 \%$, respectively) $[6,9-18]$. Of note, many of these D816V-negative patients correspond to well-differentiated SM (WDSM), a recently described rare subvariant of SM defined by skin involvement associated with clonal expansion of mature-appearing, CD25-llow $\mathrm{MCs}$ in the BM, for which specific diagnostic criteria have been proposed [19] and adopted in the new WHO 2016 classification. Of note, a significant proportion of patients with indolent forms of WDSM fail to fulfill the current WHO 2008 diagnostic criteria for SM, despite they systematically show features of a systemic MC disease such as BM $\mathrm{MC}$ aggregates, aberrant CD30 expression on BM MCs, mutations involving any region of KIT and/or a clonal nature based on the HUMARA pattern of inactivation of the X chromosome.

In the last decade, TK inhibitor (TKI) targetedtherapy (e.g. imatinib mesylate) has become the frontline treatment for several TK-driven diseases such as chronic myeloid leukemia (CML) [20], gastrointestinal stromal tumor (GIST) [21] and chronic eosinophilic leukemia (CEL)/hypereosinophilic syndrome (HES) [22]. The outstanding clinical responses obtained in these diseases have led to explore the potential utility of TKI also in mastocytosis. Data from single case reports and small series of mastocytosis patients treated with imatinib prompted the U.S. Food and Drug Administration (FDA) to approve in 2006 its use in adults with ASM lacking the D816V KIT mutation or with unknown KIT mutational status. Since then, the number of reports about D816Vnegative patients showing no response to imatinib has significantly increased, while the responding cases among D816V-negative patients include both cases with ASM as well as patients with non-advanced forms of mastocytosis.

Here we report the results of an investigator-initiated clinical trial that evaluated the efficacy of imatinib targeted therapy in 10 patients with SM -9 patients with WDSM (including $3 \mathrm{CM}, 3 \mathrm{ISM}$ and $3 \mathrm{MCL}$ ) and one SMAHNMD- lacking mutations at exon 17 of the KIT gene selected from 453 consecutive patients diagnosed with SM. Due to the rarity of these SM cases lacking exon 17 KIT mutations $(\leq 4 \%)$ [6], a critical review of mastocytosis cases treated with imatinib who have been reported in the literature is also provided to better estimate the response rates to imatinib according to the KIT mutational status.

\section{RESULTS}

\section{Clinical presentation}

Overall, 9/10 patients had WDSM according to recently proposed criteria [19] consisting of histologically-proven mastocytosis in the skin and BM compact aggregates of mature-appearing CD25-/low/CD2-/ low MCs, together with clusters of $\geq 2 \mathrm{MCs}$ outside BM particles $(n=9)$, aberrant expression of CD30 and/or overexpression of cytoplasmic proteases $(n=4)$, mutations involving exons other than exon 17 of $\operatorname{KIT}(n=3)$, a clonal HUMARA pattern of inactivation of $\mathrm{X}$ chromosome $(n=3)$, and/or female sex with either pediatric disease onset $(n=7)$ and/or familial aggregation $(n=4)$. According to the WHO 2008 classification [1], these 9 patients were subclassified as having MCL $(n=3)$, ISM $(n=3)$ and $\mathrm{CM}(n=3)$ (Table 1). Except for a patient who presented with an adult-onset mastocytoma in her right arm, all other WDSM patients referred pediatric-onset of mastocytosis-associated maculopapular skin lesions in 5 cases and diffuse cutaneous mastocytosis lesions with generalized thickening of the skin in the other 3 patients (Table 1 and Figure 1). Of note, these three later patients included two sisters and their father, who had also an associated GIST.

The remainder patient was a 37 year-old male with neither mastocytosis skin lesions nor MC-mediator release symptoms who had a 5-year history of sustained eosinophilia and increased serum tryptase (sT) levels. At referral, he showed a peripheral blood (PB) eosinophil count of $5.2 \times 10^{9} / \mathrm{L}$, increased sT levels $(32 \mu \mathrm{g} / \mathrm{L})$ and splenomegaly $(17.5 \mathrm{~cm})$. BM aspirate and biopsy analyses revealed a hypercellular marrow with increased eosinophils together with the presence of $\mathrm{CD} 25^{\text {bright }}$, spindle-shaped MCs forming compact aggregates consistent with the diagnosis of ISM-AHNMD, the associated haematological disorder being a CEL (ISMCEL).

At diagnosis, the most frequent MC-mediator release-associated symptoms were: pruritus $(n=7)$, flushing $(n=6)$, abdominal cramping $(n=4)$, diarrhea $(n=4)$ and anaphylaxis $(n=3)$ (Table 1 and Figure 3$)$. Only 2/10 patients had bone mass loss consisting of osteopenia (case \#5) and osteoporosis (case \#10).

Overall, 6 patients ( 3 advanced WDSM, 2 indolent WDSM and the ISM-CEL case) received an initial dose of imatinib of $400 \mathrm{mg}$ imatinib per day, while the other 4 WDSM patients received $300 \mathrm{mg}$ imatinib per day (Table 1).

\section{KIT mutational status and additional genetic studies}

As per the inclusion criteria, none of the 10 patients showed mutations involving exon 17 of KIT. Further 
Table 1: Clinical, biological and molecular characteristics at diagnosis and response to imatinib therapy of the 10 patients included in this study

\begin{tabular}{|c|c|c|c|c|c|c|c|c|c|c|}
\hline Findings & $\begin{array}{c}\text { Case } \\
\# 1\end{array}$ & $\begin{array}{c}\text { Case } \\
\# 2\end{array}$ & $\begin{array}{c}\text { Case } \\
\# 3\end{array}$ & $\begin{array}{c}\text { Case } \\
\# 4\end{array}$ & $\begin{array}{c}\text { Case } \\
\# 5\end{array}$ & $\begin{array}{c}\text { Case } \\
\# 6\end{array}$ & $\begin{array}{c}\text { Case } \\
\# 7\end{array}$ & $\begin{array}{c}\text { Case } \\
\# 8\end{array}$ & $\begin{array}{c}\text { Case } \\
\# 9\end{array}$ & $\begin{array}{l}\text { Case } \\
\# 10\end{array}$ \\
\hline Sex & $\mathrm{M}$ & $\mathrm{F}$ & $\mathrm{F}$ & $\mathrm{M}$ & $\mathrm{F}$ & $\mathrm{F}$ & $\mathrm{F}$ & $\mathrm{F}$ & $\mathrm{F}$ & $\mathrm{F}$ \\
\hline Age at onset/diagnosis: & $\begin{array}{c}\text { Birth/55 } \\
\mathrm{y}\end{array}$ & $\begin{array}{c}3 \mathrm{mo} / 27 \\
\mathrm{y}\end{array}$ & $3 \mathrm{mo} / 20 \mathrm{y}$ & $32 \mathrm{y} / 37 \mathrm{y}$ & $1 \mathrm{y} / 24 \mathrm{y}$ & $4 y / 26 y$ & $\begin{array}{c}14 \mathrm{y} / 21 \\
\mathrm{y}\end{array}$ & $2 \mathrm{y} / 26 \mathrm{y}$ & $\begin{array}{c}10 \mathrm{mo} / 21 \\
\mathrm{y}\end{array}$ & $60 \mathrm{y} / 69 \mathrm{y}$ \\
\hline Skin lesions & $\mathrm{DCM}$ & DCM & $\mathrm{DCM}$ & No & MPCM* & MPCM* & MPCM* & MPCM* & MPCM* & $\begin{array}{l}\text { Cutaneous } \\
\text { mastocytoma }\end{array}$ \\
\hline $\begin{array}{l}\text { Baseline MC-mediator } \\
\text { release symptoms }\end{array}$ & P,GI,D & P,Fl,GI,D & $\mathrm{P}, \mathrm{D}$ & No & $\mathrm{Fl}, \mathrm{A}$ & $\mathrm{P}$ & $\mathrm{P}, \mathrm{F}$ & $\mathrm{P}, \mathrm{Fl}, \mathrm{GI}, \mathrm{D}, \mathrm{A}$ & P,Fl,GI & $\mathrm{Fl}, \mathrm{A}$ \\
\hline BM MC aggregates & Yes & Yes & Yes & Yes & Yes & Yes & Yes & Yes & Yes & Yes \\
\hline $\begin{array}{l}>20 \% \text { of } \mathrm{MCs} \text { in BM } \\
\text { smears }\end{array}$ & Yes & Yes & No & No & No & No & No & No & No & Yes \\
\hline BM MC morpholgy & Normal & Normal & Normal & Abnormal & Normal & Normal & Normal & Normal & Normal & Normal \\
\hline BM MC phenotype & $\begin{array}{l}\text { CD2- } \\
\text { CD25- } \\
\text { CD30 }\end{array}$ & $\begin{array}{l}\mathrm{CD}^{-} \\
\mathrm{CD}^{-} 5^{-} \\
\mathrm{CD}^{-} 0^{+}\end{array}$ & $\begin{array}{l}\text { CD2- } \\
\text { CD25- } \\
\text { CD30 }\end{array}$ & $\begin{array}{c}\mathrm{CD} 2^{-} \\
\mathrm{CD} 25^{+ \text {bright }}\end{array}$ & $\begin{array}{l}\mathrm{CD} 2^{-} \\
\mathrm{CD} 25^{-}\end{array}$ & $\begin{array}{l}\mathrm{CD} 2^{-} \\
\mathrm{CD} 25^{-}\end{array}$ & $\begin{array}{l}\mathrm{CD} 2^{-} \\
\mathrm{CD} 25^{-}\end{array}$ & $\begin{array}{c}\mathrm{CD}^{\text {+low }} \\
\mathrm{CD} 25^{\text {How }} \\
\text { CD30- }\end{array}$ & $\begin{array}{l}\mathrm{CD}^{\text {+low }} \\
\text { CD25- } \\
\text { CD30- }\end{array}$ & $\begin{array}{l}\text { CD2 } 2^{\text {+low }} \\
\text { CD25- } \\
\text { CD30- }\end{array}$ \\
\hline KIT mutation & K509I & K509I & K509I & Negative & Negative & Negative & Negative & Negative & Negative & Negative \\
\hline HUMARA & NA & NA & Polyclonal & NA & Clonal & Polyclonal & Clonal & Clonal & Polyclonal & Polyclonal \\
\hline Organomegalies & No & No & No & $\mathrm{S}$ & $\mathrm{L}$ & No & No & No & $\mathrm{L}$ & No \\
\hline C-findings & No & No & No & No & No & No & No & No & No & No \\
\hline Associated diseases & GIST & GIST & GIST & CEL & No & No & No & No & No & No \\
\hline $\begin{array}{l}\text { WHO diagnostic } \\
\text { subtype }\end{array}$ & MCL & MCL & ISM & $\begin{array}{c}\text { SM- } \\
\text { AHNMD }\end{array}$ & $\mathrm{CM}$ & $\mathrm{CM}$ & $\mathrm{CM}$ & ISM & ISM & MCL \\
\hline WDSM criteria [19] & Yes & Yes & Yes & No & Yes & Yes & Yes & Yes & Yes & Yes \\
\hline Advanced MC disease $\dagger$ & Yes & Yes & No & Yes & No & No & No & No & No & Yes \\
\hline Prior therapies & DCG,H1 & DCG,H1 & DCG,H1 & HU,CS & DCG,H1 & $\mathrm{H} 1$ & H1 & DCG,H1 & DCG,H1 & $\begin{array}{l}\text { DCG,H1, } \\
\text { H2,LTA }\end{array}$ \\
\hline \multicolumn{11}{|l|}{$\begin{array}{l}\text { Imatinib dosage (mg/ } \\
\text { day) }\end{array}$} \\
\hline Initial prescribed dosage & 400 & 400 & 400 & 400 & 300 & 300 & 300 & 300 & 400 & 400 \\
\hline Dosage reduction & No & 300 & 300 & 300 & No & No & No & No & No & 300 \\
\hline \multicolumn{11}{|l|}{ BM MCs by IHC (\%) } \\
\hline Before imatinib & 60 & 80 & 20 & 15 & 5 & 5 & 5 & 5 & 40 & 65 \\
\hline$+6 \mathrm{mo}$ & $<1$ & $<1$ & $<1$ & $<1$ & NA & NA & NA & NA & 40 & 80 \\
\hline$+12 \mathrm{mo}$ & $<1$ & $<1$ & $<1$ & $<1$ & 3 & 5 & 5 & 5 & NA & NA \\
\hline \multicolumn{11}{|l|}{ BM MCs by FC (\%) } \\
\hline Before imatinib & 7 & 13 & 0.78 & 0.28 & 0.01 & 0.02 & 0.01 & 0.06 & 0.4 & 14 \\
\hline$+6 \mathrm{mo}$ & 0.02 & 0.007 & 0.0009 & 0.0009 & NA & NA & NA & NA & 0.4 & 19 \\
\hline$+12 \mathrm{mo}$ & 0.01 & 0.003 & 0.0005 & 0.0007 & 0.005 & 0.03 & 0.03 & 0.09 & NA & NA \\
\hline \multicolumn{11}{|l|}{ sT levels $(\mu \mathrm{g} / \mathrm{L})$} \\
\hline Before imatinib & 90.9 & 126 & 43.8 & 46.9 & 18.1 & 11.0 & 8.6 & 16.7 & 386 & 196 \\
\hline$+6 \mathrm{mo}$ & 3.2 & 4.9 & 1.6 & 2.3 & 14.7 & 9.6 & 4.8 & 10.5 & 385 & 244 \\
\hline$+12 \mathrm{mo}$ & 1.6 & 3.1 & 1.4 & 1.8 & 14.7 & 9.5 & 4.8 & 8.9 & NA & NA \\
\hline $\begin{array}{l}\text { Response to therapy } \\
(+6 \mathrm{mo} /+12 \mathrm{mo})\end{array}$ & $\mathrm{CR} / \mathrm{CR}$ & $\mathrm{CR} / \mathrm{CR}$ & $\mathrm{CR} / \mathrm{CR}$ & $\mathrm{CR} / \mathrm{CR}$ & NA/PR & NA/NR & NA/NR & $\mathrm{NA} / \mathrm{NR}$ & NR/NA & NR/NA \\
\hline
\end{tabular}

M, male; F, female; y, years; mo, months; DCM, diffuse cutaneous mastocytosis; MPCM, maculopapular cutaneous mastocytosis; P, pruritus; Fl, flushing; GI, gastrointestinal pain; D, diarrhea; A, anaphylaxis; BM, bone marrow; MC, mast cell; HUMARA, human androgen receptor assay; NA, not assessed/ applicable; S, splenomegaly; L, hepatomegaly; GIST, gastrointestinal stromal tumor; CEL, chronic eosinophilic leukemia; WHO, World Health Organization; MCL, mast cell leukemia; ISM, indolent systemic mastocytosis;; SM-AHNMD, systemic mastocytosis with associated clonal hematological non-MC disease; CM, cutaneous mastocytosis; WDSM, well-differentiated systemic mastocytosis; DCG, disodium cromoglycate; H1, H1 blockers; HU, hydroxyurea; CS, corticosteroids; H2, H2 blockers; LTA, leukotriene antagonists; IHC, immunohistochemistry; FC, flow cytometry; sT, serum tryptase; CR, complete response; PR, partial response; NR, no response.

$\$$ Age at onset was defined as that at which mastocytosis-associated features (e.g. increased serum tryptase for patient \#4 and emergence of skin lesions for the remaining patients) were first noticed, while age at diagnosis as that at which systemic disease was confirmed by BM studies.

*These cases corresponded to the monomorphic variant of MPCM according to a novel consensus classification of CM proposed by the ECNM [24].

$\dagger$ Defined as the presence of C-findings, $>20 \%$ of MCs in BM smears and/or an associated clonal non-MC lineage haematological disease. 
sequencing of other KIT exons revealed a germline K509I mutation (exon 9) in the 3 familial WDSM patients (Table 1). In the SM-CEL patient, Janus kinase $2(J A K-2)$ gene mutations, rearrangements of the platelet-derived growth factor receptor (PDGFR) $\alpha$ and $\beta$ genes, and T-cell clonality were ruled out, while genetic analyses for the fibroblast growth factor receptor 1 (FGFR1) gene were not performed.
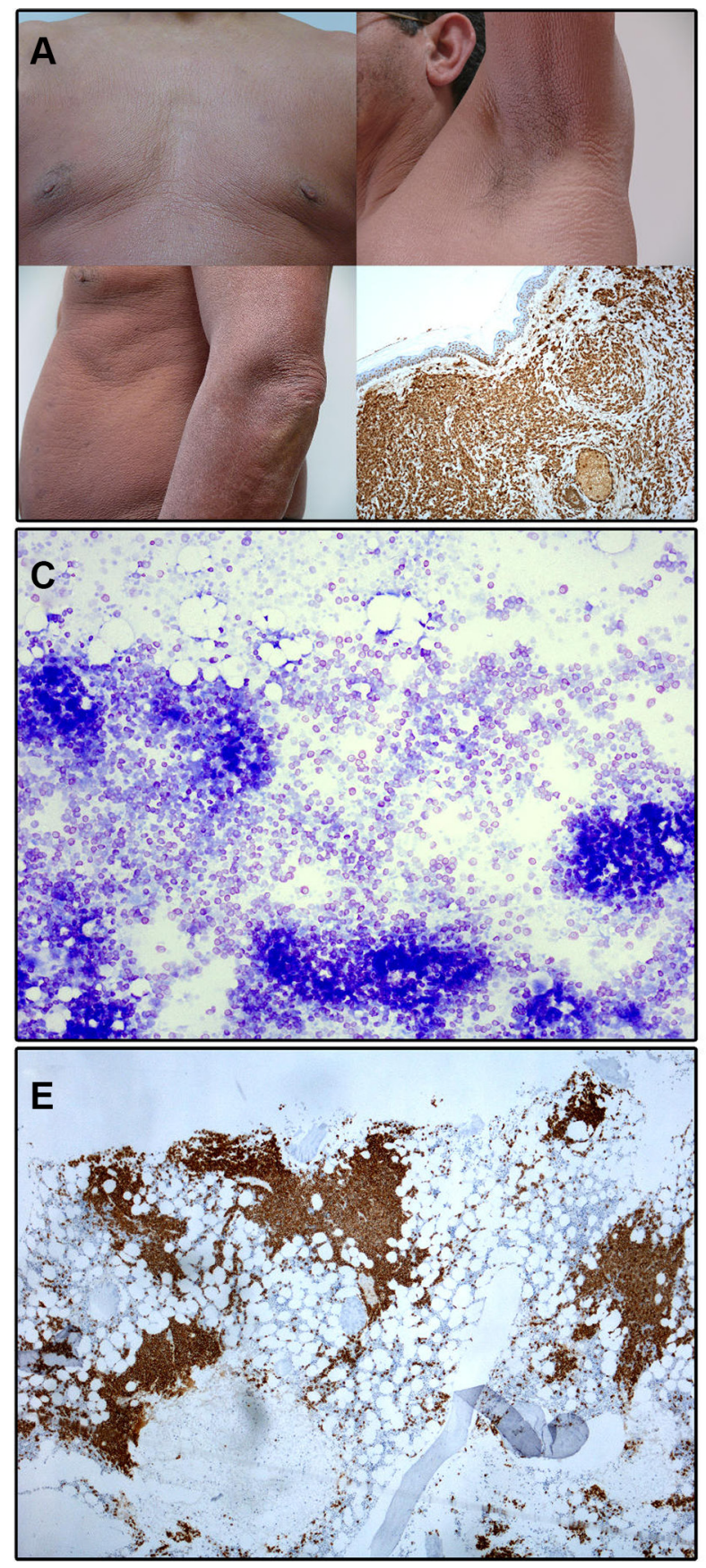

\section{Toxicity}

Imatinib was reduced from $400 \mathrm{mg}$ to $300 \mathrm{mg}$ in 2 patients (cases \#2 and \#3) due to grade 3 gastrointestinal symptoms. In another two patients receiving $400 \mathrm{mg} /$ day (cases \#4 and \#10), treatment was transiently stopped due to grade 4 neutropenia and grade 4 anemia which were successfully recovered with G-CSF support and red
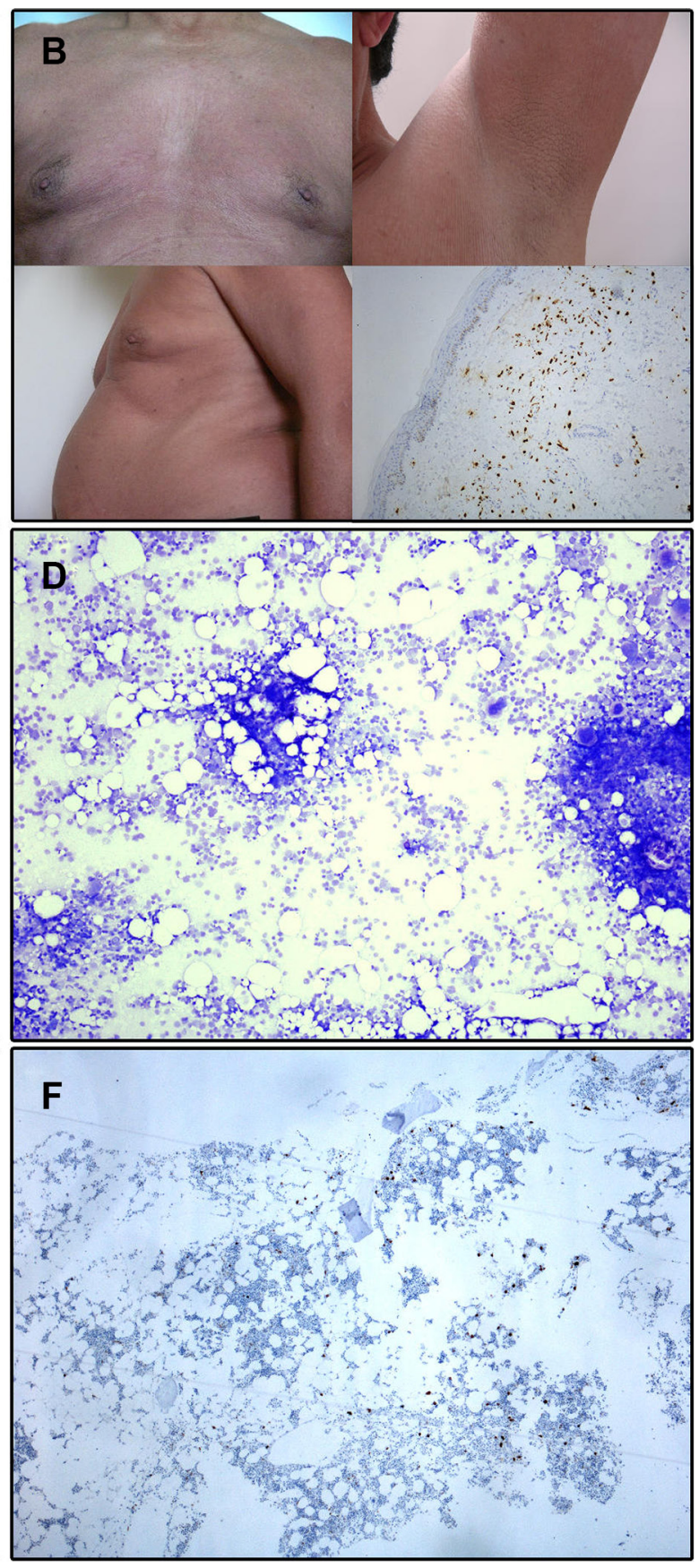

Figure 1: Illustrating skin and bone marrow microscopic images obtained before and at month +12 of imatinib therapy in a patient with advanced WDSM who achieved CR (case \#1). (A-B) Macroscopic appearance of the skin and histological findings of skin biopsy (tryptase stain, 100x magnification) at diagnosis (A) and after imatinib therapy (B). (C-D) BM smears (toluidine blue stain, 100x magnification) at diagnosis (C) and after imatinib therapy (D). (E-F) BM sections (c-kit stain, 100x magnification) at diagnosis (E) and after imatinib therapy (F). 
blood cell transfusions, respectively; afterward, imatinib was reintroduced in both cases at $300 \mathrm{mg}$ /day with no further haematological toxicity. Grade $\leq 2$ adverse events included: muscle cramps $(70 \%)$, nausea $(50 \%)$, edema $(40 \%)$, skin rash $(20 \%)$, alopecia (20\%), dyspepsia (10\%) and abdominal pain (10\%).

\section{Response to therapy}

Overall, objective responses were obtained in $5 / 10$ patients including $\mathrm{CR}$ in 4 of the 5 responder patients ( 2 advanced WDSM, 1 indolent WDSM and the SM-CEL patient), and PR in another indolent WDSM case (Table 1). All 4 patients who achieved CR showed complete clearance of $\mathrm{BM} \mathrm{MC}$ infiltrates (together with negative expression of CD25 on BM MCs and a dramatic decrease of BM eosinophil counts in the SMCEL patient) at month +6 of therapy; in all four cases, CR was maintained at month +12 of therapy (Table 1 and Figures 1 and 2). In parallel, all four CR cases also showed early normalization of sT levels (Table 1 and Figure 2), as well as complete disappearance of MC-mediator releaseassociated symptoms (Figure 3) and gradual improvement of skin lesions in those 3 patients who had cutaneous involvement, as histologically confirmed at the end of the study (Figure 1). Noteworthy, treatment with imatinib was continued beyond the end of the study in these 3 later patients because of the presence of an associated GIST. At
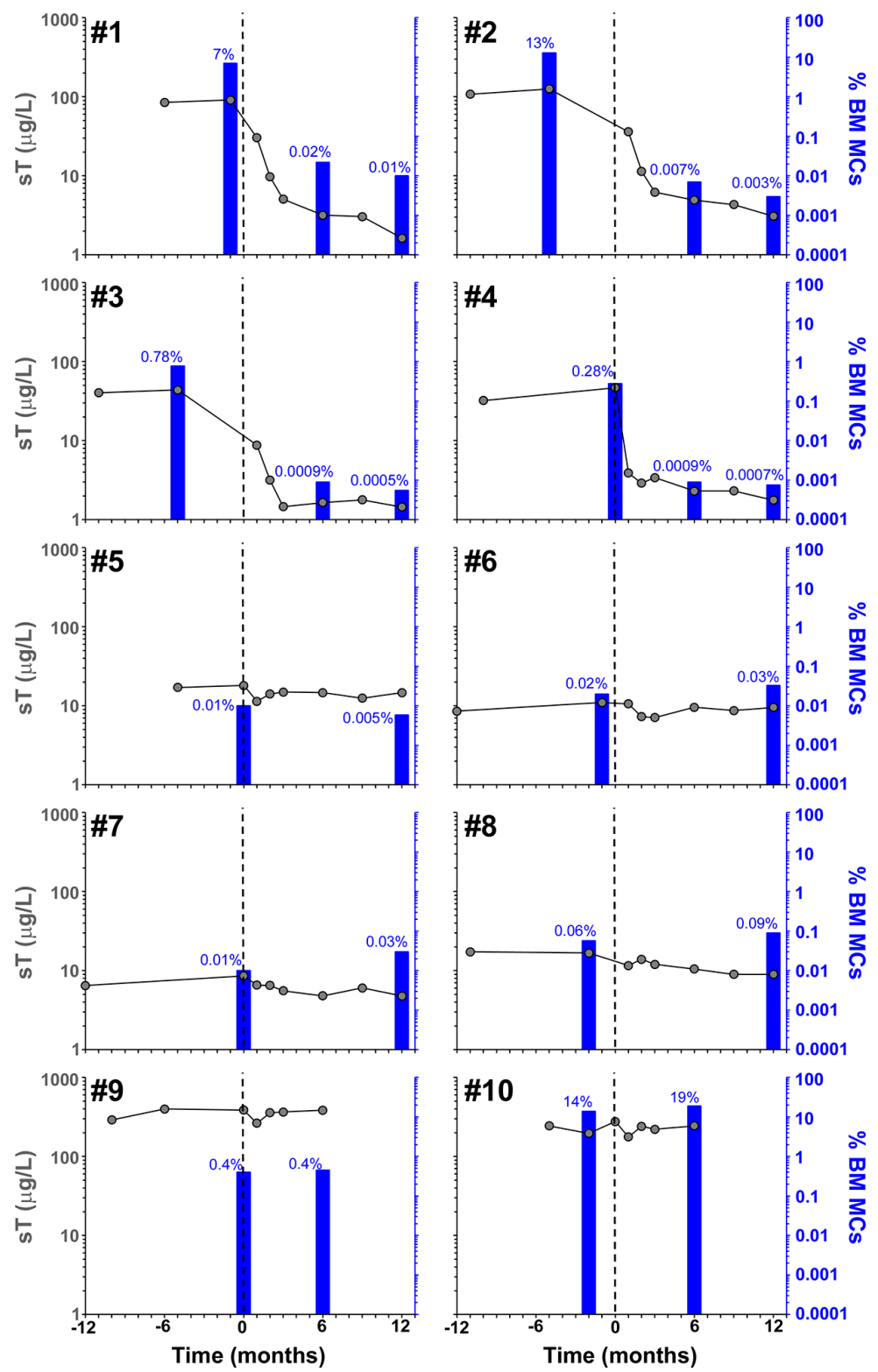

Figure 2: Effect of imatinib therapy on BM MC counts and sT levels in the $\mathbf{1 0}$ patients included in the present clinical trial. Vertical dotted lines indicate start of imatinib therapy, blue bars and grey dots represent the percentage of pathologic/aberrant BM MCs as assessed by flow cytometry and sT values, respectively, before and after imatinib therapy. 
last follow-up (e.g. 72 months after initiation of imatinib in case \#1 and 66 months after starting on imatinib in cases \#2 and \#3), all three patients still showed sT levels < $5 \mu \mathrm{g} / \mathrm{L}$, normal skin appearance and neither MC-mediator release symptoms nor drug-associated long-term side
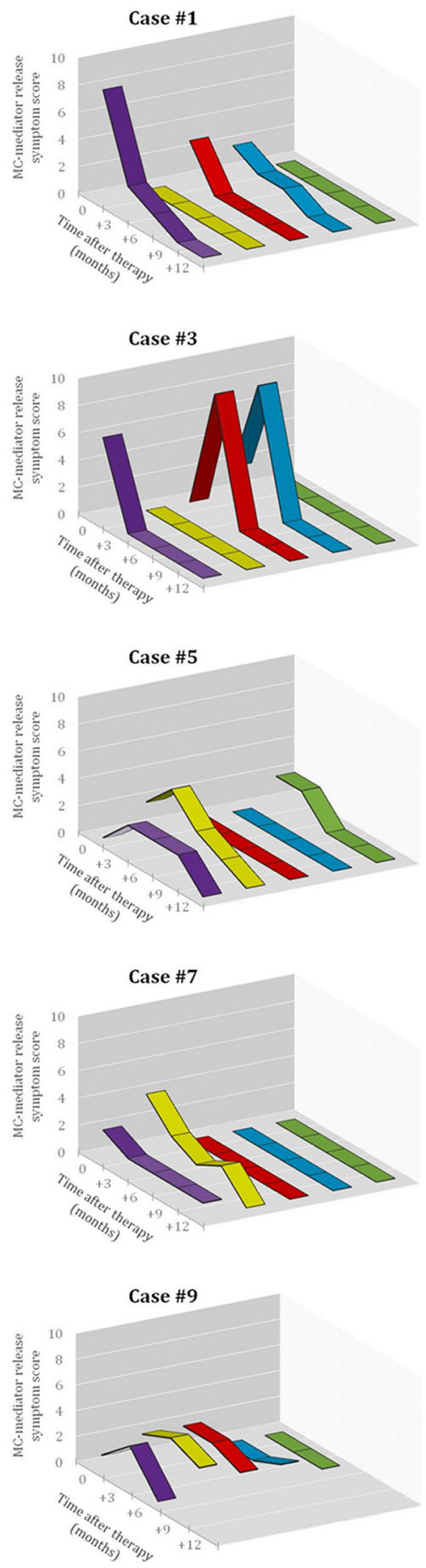

effects; although no further BM studies were performed, these findings suggest that they remained in continuous CR of their SM. In turn, repeated CT scans during the follow-up period showed no significant changes of GIST lesions in these three patients. In the SM-CEL case, the PB
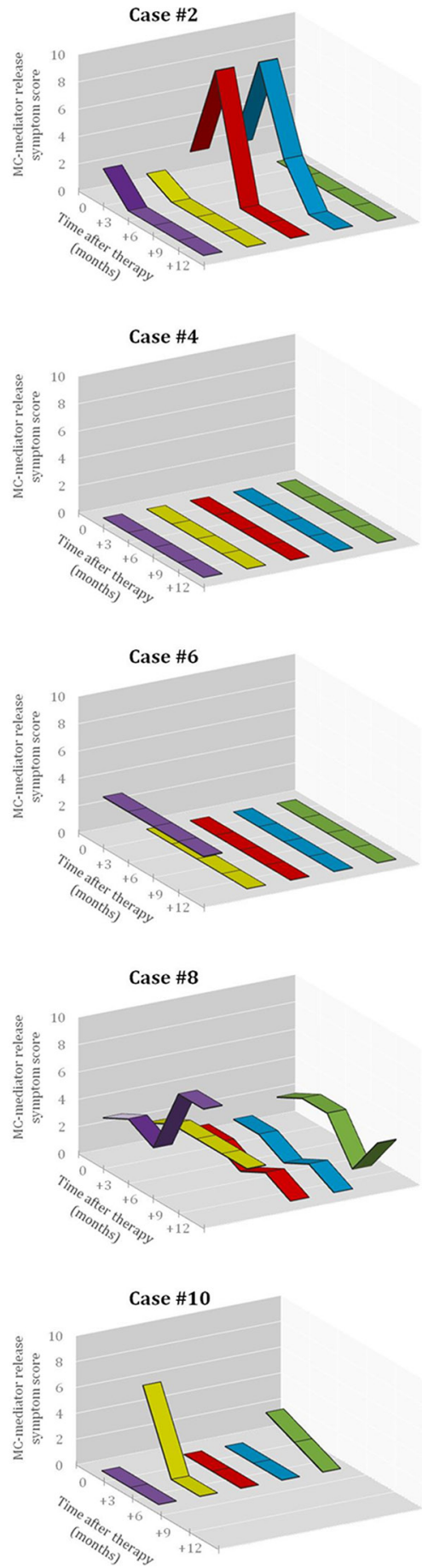

Figure 3: Effect of imatinib therapy on MC-mediator release associated symptoms in the 10 patients included in the present clinical trial. Symptomatic response was evaluated in each patient before starting imatinib and every 3 months thereafter using Likert-type scales obtained from specific questionnaires designed by the REMA, by which MC-mediator release symptoms (e.g. pruritus, purple lane; flushing, yellow lane; abdominal cramping, red lane; diarrhea, blue lane; and anaphylaxis, green lane) were graded as described in detail in the Methods section. The X-axis represents the different time-points at which the questionnaires were collected, while the Y-axis represents the overall score (i.e. the frequency score multiplied by the severity score) for each MC-mediator release-associated symptom. 
eosinophil count decreased to $0.1 \times 10^{9} / \mathrm{L}$ after 4 weeks of therapy and remained below $0.4 \times 10^{9} / \mathrm{L}$ thereafter; in addition, splenomegaly had disappeared at the end of the study. In view of these results imatinib was discontinued, and both eosinophil counts as well as sT levels remained within normal range for 5 additional years. Of note, in 3/4 CR patients, KIT mutations in exon 9 had been detected (Table 1).

The only patient who attained PR showed 50\% decrease of BM MCs by flow cytometry (Table 1 and Figure 2) in the absence of BM MC aggregates, together with resolution of pre-existing (mild) hepatomegaly. In parallel, sT levels decreased by $20 \%$ (Table 1 and Figure 2), MC-mediator release-associated symptoms completely disappeared (Figure 3) and modest fading of skin lesions was observed at month +12 . The patient kept under imatinib treatment for one additional year, during which no further MC-mediator release-associated symptoms occurred and both sT levels and skin lesions remained stable; thereafter, she decided to get pregnant and thereby, treatment was discontinued.

Among the 5 non-responders, imatinib was discontinued at month +6 of therapy in two patients with advanced SM due to lack of response upon BM re-evaluation (Table 1 and Figure 2). Despite this, both patients showed improvement of symptoms at that time (Figure 3). In the remaining 3 patients who completed the trial, neither a significant reduction of BM MC numbers (Table 1 and Figure 2), nor changes in skin lesions were observed. Despite this, sT levels decreased in all 3 patients by $13 \%, 44 \%$ and $46 \%$ (Table 1 and Figure 2), in parallel to a mild decrease of MC-mediator release-associated symptoms in one patient (Figure 3 ). All five refractory patients had wild-type KIT (Table 1).

\section{DISCUSSION}

Currently, SM remains an incurable disease. SM patients are typically managed with drugs aimed at improving and/or preventing symptoms related to the release of $\mathrm{MC}$ mediators, together with cytoreductive therapy in advanced cases (e.g. ASM, MCL and SMAHNMD). Interferon- $\alpha$ and cladribine are the most commonly used cytotoxic agents to decrease MC tumor load in advanced SM patients; unfortunately, objective responses occur in only $20-30 \%$ of cases and these typically consist of transient PR [25, 26].

In the last decade, TKI targeted-therapy (e.g. imatinib mesylate) has emerged as a new promising treatment approach for a subset of mastocytosis patients. In vitro studies on $\mathrm{MC}$ lines and human BM MCs have shown that imatinib inhibits phosphorylation of KIT and growth of MCs with wild-type KIT or mutations localized outside the activation loop (e.g. exon 17) of KIT such as the V560G, F522C, K509I or p.419del mutations [10-12, 27-29]; in contrast, the D $816 \mathrm{~V}$ KIT mutation confers constitutive resistance to the drug [30]. These preclinical findings correlated well with early reports showing response to imatinib in $18 / 26$ patients $(69 \%)$ who either lacked or were not screened for the D816V KIT mutation vs. 1/4 D816V-positive cases (25\%) [12, 31-39]. These observations led to the approval by the FDA of imatinib for adult ASM patients who have no D816V KIT mutation or with unknown KIT mutational status; however, it should be noted that 10 out of those 18 responding cases previously evaluated by the FDA who were negative or not tested for the D816V KIT mutation, showed either the FIP1L1/PDGFR $\alpha$ fusion gene $(n=8)$ or juxtamembrane KIT mutations $(n=2)$, which might have contributed to an overestimation of the impact of the absence of the D816V KIT mutation itself in the response to imatinib in that series of patients.

To date, 121 mastocytosis patients, plus the 10 patients studied here, have been reported as being treated with imatinib for a total of 131 cases; from them, response to therapy data is publicly available for $128 / 131$ patients (Table 2). The overall reported response rate to imatinib among patients with either no D816V KIT mutation or unknown KIT mutational status vs. D $816 \mathrm{~V}$ KIT mutationpositive patients is of $57 \%$ vs. $46 \%$, respectively. However, highly heterogeneous response criteria have been used in different reports, e.g. while in some reports response to imatinib was defined by a substantially reduced degree of $\mathrm{BM} \mathrm{MC}$ infiltration, in other series, patients were classified as responders whenever they showed improvement of symptoms related to the release of MC mediators after treatment. Such variability is due, at least in part, to the lack of consensus treatment response criteria for mastocytosis until 2007, when a first proposal was formulated [40]. More recently, specific response criteria for advanced mastocytosis have been redefined by the International Working Group-Myeloproliferative Neoplasms Research and Treatment (IWG-MRT) and the European Competence Network on Mastocytosis (ECNM) [41]; in turn, response criteria in terms of $\mathrm{MC}$ tumor load are still lacking for patients with non-aggressive (e.g.CM and ISM) forms of mastocytosis. In the trial here described, homogeneous and well-defined response criteria were used to evaluate both the reduction in BM MC burden and the improvement of symptoms related to the activation of MCs, as described above in detail. In addition, sequencing of exons other than exon 17 of KIT in highly-purified BM MCs [4, 23] allowed for reliable discrimination between those three cases who had KIT mutations involving exon 9 of KIT (e.g. K509I) and the seven patients with wild-type $K I T$.

Overall, half of our cases showed response to imatinib, this consisting of CR by the recent ECNM consensus criteria [41] in all but one case. Interestingly, except for one patient with SM-CEL, CR was restricted to WDSM patients showing mutations in exon 9 (K509I) of $K I T$, whereas all non-responder cases had wild-type 
Table 2: Response to imatinib in mastocytosis patients included in the present study and in previous reports

\begin{tabular}{|c|c|c|c|c|c|c|c|c|c|c|c|c|c|c|c|c|c|c|}
\hline \multirow{3}{*}{ Year } & \multirow{3}{*}{ Ref } & \multicolumn{5}{|c|}{ Number of patients } & \multicolumn{6}{|c|}{ Reported responses } & \multicolumn{6}{|c|}{$\begin{array}{c}\text { Response referred to as MC } \\
\text { cytoreduction }\end{array}$} \\
\hline & & \multirow{2}{*}{ है } & \multirow{2}{*}{ 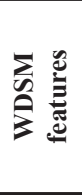 } & \multirow{2}{*}{ 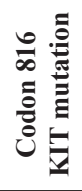 } & \multirow{2}{*}{ 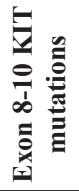 } & \multirow{2}{*}{ 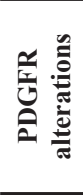 } & \multicolumn{4}{|c|}{ Type of response } & \multicolumn{2}{|c|}{ Response rate } & \multicolumn{4}{|c|}{ Type of response } & \multicolumn{2}{|c|}{ Response rate } \\
\hline & & & & & & & CR & PR & NR & NA & ORR \$ & CRR & CR & PR & NR & NA & ORR & CRR \\
\hline 2003 & {$[31]$} & $1 \dagger$ & NA & NA & NA & NA & 0 & 0 & 1 & 0 & $0 / 1$ & $0 / 1$ & 0 & 0 & 1 & 0 & $0 / 1$ & $0 / 1$ \\
\hline 2003 & {$[32,33]$} & $12 \dagger$ & NA & 2 & 0 & 3 & 3 & 4 & 3 & 2 & $7 / 10$ & $3 / 10$ & 3 & 2 & 2 & 5 & $5 / 7$ & $3 / 7$ \\
\hline 2004 & {$[34]$} & $1 \dagger$ & 0 & 0 & NA & 1 & 1 & 0 & 0 & 0 & $1 / 1$ & $1 / 1$ & 1 & 0 & 0 & 0 & $1 / 1$ & $1 / 1$ \\
\hline 2004 & {$[35]$} & $3 \dagger$ & NA & 0 & 0 & 0 & 0 & 2 & 1 & 0 & $2 / 3$ & $0 / 3$ & 0 & 0 & 0 & 3 & NA & NA \\
\hline 2004 & {$[36]$} & $1 \dagger$ & NA & 1 & NA & NA & 0 & 0 & 1 & 0 & $0 / 1$ & $0 / 1$ & 0 & 0 & 1 & 0 & $0 / 1$ & $0 / 1$ \\
\hline 2004 & {$[10]$} & $1 \dagger$ & 1 & 0 & 1 & NA & 0 & 1 & 0 & 0 & $1 / 1$ & $0 / 1$ & 0 & 1 & 0 & 0 & $1 / 1$ & $0 / 1$ \\
\hline 2004 & [37] & $9 \dagger$ & NA & 2 & NA & 4 & 4 & 0 & 5 & 0 & $4 / 9$ & $4 / 9$ & 1 & 0 & 5 & 3 & $1 / 6$ & $1 / 6$ \\
\hline 2005 & {$[38]$} & $1 \dagger$ & 0 & 1 & 0 & NA & 1 & 0 & 0 & 0 & $1 / 1$ & $1 / 1$ & 1 & 0 & 0 & 0 & $1 / 1$ & $1 / 1$ \\
\hline 2006 & {$[12]$} & $1 \dagger$ & 1 & 0 & 1 & NA & 0 & 1 & 0 & 0 & $1 / 1$ & $0 / 1$ & 0 & 0 & 0 & 1 & NA & NA \\
\hline 2006 & [45] & 14 & NA & 11 & NA & 1 & 1 & 10 & 3 & 0 & $11 / 14$ & $1 / 14$ & 0 & 3 & 6 & 5 & $3 / 9$ & $0 / 9$ \\
\hline 2006 & [46] & 1 & 0 & 0 & NA & 1 & 1 & 0 & 0 & 0 & $1 / 1$ & $1 / 1$ & 0 & 0 & 0 & 1 & NA & NA \\
\hline 2006 & [47] & 1 & NA & 0 & NA & 1 & 1 & 0 & 0 & 0 & $1 / 1$ & $1 / 1$ & 0 & 0 & 0 & 1 & NA & NA \\
\hline 2007 & [65] & 1 & NA & NA & NA & NA & 0 & 0 & 1 & 0 & $0 / 1$ & $0 / 1$ & 0 & 0 & 1 & 0 & $0 / 1$ & $0 / 1$ \\
\hline 2007 & [63] & 1 & 0 & NA & NA & 1 & 1 & 0 & 0 & 0 & $1 / 1$ & $1 / 1$ & 1 & 0 & 0 & 0 & $1 / 1$ & $1 / 1$ \\
\hline 2007 & {$[64]$} & 1 & NA & NA & NA & NA & 0 & 1 & 0 & 0 & $1 / 1$ & $0 / 1$ & 0 & 1 & 0 & 0 & $1 / 1$ & $0 / 1$ \\
\hline 2008 & {$[62]$} & 1 & 0 & 0 & 0 & 1 & 1 & 0 & 0 & 0 & $1 / 1$ & $1 / 1$ & 1 & 0 & 0 & 0 & $1 / 1$ & $1 / 1$ \\
\hline 2008 & {$[48]$} & 1 & 0 & 0 & NA & NA & 0 & 1 & 0 & 0 & $1 / 1$ & $0 / 1$ & 0 & 0 & 0 & 1 & NA & NA \\
\hline 2008 & [49] & 17 & NA & NA & NA & NA & 1 & 4 & 12 & 0 & $5 / 17$ & $1 / 17$ & 1 & 4 & 12 & 0 & $5 / 17$ & $1 / 17$ \\
\hline 2008 & {$[46]$} & 1 & NA & 0 & 1 & NA & 0 & 1 & 0 & 0 & $1 / 1$ & $0 / 1$ & 0 & 0 & 0 & 1 & NA & NA \\
\hline 2008 & [39] & $5 \dagger$ & NA & 5 & 0 & 0 & 0 & 1 & 4 & 0 & $1 / 5$ & $0 / 5$ & 0 & 0 & 0 & 5 & NA & NA \\
\hline 2008 & {$[50]$} & 5 & 0 & 3 & NA & NA & 0 & 2 & 3 & 0 & $2 / 5$ & $0 / 5$ & 0 & 0 & 0 & 5 & NA & NA \\
\hline 2009 & {$[66]$} & 1 & 0 & 1 & 0 & 0 & 0 & 0 & 1 & 0 & $0 / 1$ & $0 / 1$ & 0 & 0 & 0 & 1 & NA & NA \\
\hline 2009 & {$[51]$} & 20 & 0 & 13 & NA & 0 & 1 & 6 & 13 & 0 & $7 / 20$ & $1 / 20$ & 1 & 0 & 19 & 0 & $1 / 20$ & $1 / 20$ \\
\hline 2011 & [17] & 1 & 1 & 0 & 1 & NA & 0 & 1 & 0 & 0 & $1 / 1$ & $0 / 1$ & 0 & 1 & 0 & 0 & $1 / 1$ & $0 / 1$ \\
\hline 2011 & {$[52]$} & 1 & 0 & 0 & NA & NA & 0 & 1 & 0 & 0 & $1 / 1$ & $0 / 1$ & 0 & 0 & 0 & 1 & NA & NA \\
\hline 2011 & [53] & 1 & 0 & 0 & 0 & 0 & 1 & 0 & 0 & 0 & $1 / 1$ & $1 / 1$ & 1 & 0 & 0 & 0 & $1 / 1$ & $1 / 1$ \\
\hline 2012 & {$[42]$} & 2 & 0 & 0 & 1 & NA & 1 & 0 & 1 & 0 & $1 / 2$ & $1 / 2$ & 1 & 0 & 1 & 0 & $1 / 2$ & $1 / 2$ \\
\hline 2012 & {$[18]$} & 1 & 1 & 0 & 0 & NA & 1 & 0 & 0 & 0 & $1 / 1$ & $1 / 1$ & 1 & 0 & 0 & 0 & $1 / 1$ & $1 / 1$ \\
\hline 2012 & {$[58]$} & 1 & 0 & 0 & 0 & 0 & 0 & 0 & 1 & 0 & $0 / 1$ & $0 / 1$ & 0 & 0 & 1 & 0 & $0 / 1$ & $0 / 1$ \\
\hline 2012 & {$[67]$} & 1 & 0 & NA & NA & NA & 0 & 0 & 1 & 0 & $0 / 1$ & $0 / 1$ & 0 & 0 & 1 & 0 & $0 / 1$ & $0 / 1$ \\
\hline 2013 & {$[16]$} & 1 & NA & 0 & 1 & 0 & 0 & 0 & 0 & 1 & NA & NA & 0 & 0 & 0 & 1 & NA & NA \\
\hline 2013 & {$[54]$} & 1 & 0 & 0 & NA & NA & 1 & 0 & 0 & 0 & $1 / 1$ & $1 / 1$ & 1 & 0 & 0 & 0 & $1 / 1$ & $1 / 1$ \\
\hline 2013 & [43] & 2 & NA & 0 & 2 & NA & 2 & 0 & 0 & 0 & $2 / 2$ & $2 / 2$ & 0 & 0 & 0 & 2 & NA & NA \\
\hline 2013 & {$[55]$} & 1 & NA & 0 & NA & 0 & 0 & 1 & 0 & 0 & $1 / 1$ & $0 / 1$ & 0 & 0 & 0 & 1 & NA & NA \\
\hline 2013 & [59] & 1 & 0 & 0 & 0 & 0 & 0 & 0 & 1 & 0 & $0 / 1$ & $0 / 1$ & 0 & 0 & 1 & 0 & $0 / 1$ & $0 / 1$ \\
\hline 2014 & {$[14]$} & 1 & 1 & 0 & 1 & $\mathrm{NA}$ & 1 & 0 & 0 & 0 & $1 / 1$ & $1 / 1$ & 1 & 0 & 0 & 0 & $1 / 1$ & $1 / 1$ \\
\hline 2014 & {$[15]$} & 2 & 2 & 0 & 2 & $\mathrm{NA}$ & 2 & 0 & 0 & 0 & $2 / 2$ & $2 / 2$ & 2 & 0 & 0 & 0 & $2 / 2$ & $2 / 2$ \\
\hline 2014 & {$[60]$} & 1 & 0 & 0 & NA & 0 & 0 & 0 & 1 & 0 & $0 / 1$ & $0 / 1$ & 0 & 0 & 1 & 0 & $0 / 1$ & $0 / 1$ \\
\hline 2014 & {$[56]$} & 1 & 0 & 0 & 0 & NA & 0 & 1 & 0 & 0 & $1 / 1$ & $0 / 1$ & 0 & 0 & 0 & 1 & NA & NA \\
\hline 2015 & {$[57]$} & 1 & NA & 0 & 0 & 0 & 0 & 1 & 0 & 0 & $1 / 1$ & $0 / 1$ & 0 & 0 & 0 & 1 & NA & NA \\
\hline 2015 & {$[61]$} & 1 & 0 & 0 & 0 & NA & 0 & 0 & 1 & 0 & $0 / 1$ & $0 / 1$ & 0 & 0 & 1 & 0 & $0 / 1$ & $0 / 1$ \\
\hline \multirow[t]{3}{*}{2016} & $*$ & 10 & 9 & 0 & 3 & $\mathrm{NA}$ & 4 & 1 & 5 & 0 & $5 / 10$ & $4 / 10$ & 4 & 1 & 5 & 0 & $5 / 10$ & $4 / 10$ \\
\hline & Total & 131 & 16 & 39 & 14 & 13 & 29 & 40 & 59 & 3 & $69 / 128$ & $29 / 128$ & 21 & 13 & 58 & 39 & $34 / 92$ & $21 / 92$ \\
\hline & & & & & & & & & & & $(53 \%)$ & $(23 \%)$ & & & & & $(37 \%)$ & $(23 \%)$ \\
\hline
\end{tabular}

Ref, reference number in this manuscript; N, number of patients; WDSM, well-differentiated systemic mastocytosis; PDGFR, platelet-derived growth factor receptor; MC, mast cell; $\mathrm{CR}$, complete response; PR, partial response; NR, no response; NA, not available; ORR, overall response rate; CRR, complete response rate.

*This study corresponds to the clinical trial here reported.

$\dagger$ Cases evaluated by the FDA. The study with reference number [39] was a manufacturer-sponsored clinical trial whose results were published after FDA approval.

IORR is defined as the proportion of patients who achieve CR or PR. 
KIT. To date, 7 adult SM patients showing mutations at exons other than exon 17 of KIT (exons 9 and 10) have been reported to be treated with imatinib. Five patients had the K509I KIT mutation (3 ISM, 1 ASM and 1 MCL) [12, 14-16], 1 ASM patient had the F522C KIT mutation [10] and 1 MCL patient carried the p.A502-Y503dup at exon 9 [17]. One of the ISM patients carrying the K509I mutation had a concomitant GIST that did not respond to imatinib, and the response of ISM was not assessed/ reported in this case [16]. Interestingly, SM and GIST also coexisted in our 3 familial cases who had the K509I mutation; in these 3 cases SM showed CR but the GISTs were unresponsive to imatinib. In the other 6 previously reported patients with exon 9 or 10 KIT mutations, CR or near CR of mastocytosis was reported [10, 12, 14, 15, 17]. Of note, all 6 responding patients reported previously, as well as the three $\mathrm{K}^{2} 09 \mathrm{I}^{+}$patients who achieved $\mathrm{CR}$ in our series, were diagnosed with WDSM or had features highly suggestive of such variant of SM (e.g. childhood onset, female gender, familial aggregation and matureappearing, round shape CD25- BM MCs), supporting the close association of mutations involving the extracellular membrane and transmembrane domains of the KIT gene with WDSM [19]. Similarly, objective responses to imatinib have been also reported in 3 children with CM and 1 adult patient with MC sarcoma showing deletion of codon 419 (p.419del) in exon 8 of KIT, a region located within the extracellular domain of the gene [42-44]. Altogether, these findings suggest that the presence of mutations involving the extracellular and transmembrane domains of KIT (exons 8 to 10) is strongly associated with response to imatinib in mastocytosis.

In contrast, our results also suggest that response to imatinib among SM patients who have wild-type $K I T$ is limited, with only $1 / 6$ cases achieving PR. Overall, 46 patients with mastocytosis lacking the D816V KIT mutation and other extracellular membrane/ transmembrane KIT mutations who were treated with imatinib and further evaluated for response to therapy have been reported, with an overall response rate of $80 \%(37 / 46$ cases) [18, 32-35, 37, 42, 45-62]. However, almost one third of such responding cases corresponded to patients with SM associated with either HES/CEL $(n=11 / 37)$ [32, $34,37,45-47]$ or chronic basophilic leukemia $(n=1 / 37)$ [68] carrying rearrangements of $P D G F R \alpha / P D G F R \beta$; in turn, another $10 / 37$ patients only showed improvement of MC-mediator release-associated symptoms and/or skin lesions [32, 48, 51, 52, 55, 57] Among the remaining 15 cases, 5 fulfilled criteria for CR $[18,49,51,53,54]$ and 10 were reported to have PR [32, 45, 49, 50, 56]. It should be noted that unlike $\mathrm{CR}$, which was defined in all reports by the disappearance of all mastocytosis-related signs and symptoms together with decrease of sT levels to $<20 \mu \mathrm{g} / \mathrm{L}$, criteria used for establishing PR were more heterogeneous, a significant reduction of $\mathrm{BM} \mathrm{MC}$ infiltrates being documented in only 4/10 PR patients $[32,45]$. Altogether, these observations suggest that applying the more strict response criteria used in the present study, previously reported response of D816V-negative patients to imatinib therapy would probably had been lower. In fact, when only those patients who showed significant MC cytoreduction (e.g. $\geq 50 \%$ ) after therapy are considered, and those with PDGFR rearrangements are excluded, the overall response rate to imatinib decreases to $25 \%$, which is quite similar to that found in our clinical trial for this patient subgroup. A potential explanation for this low "true" response rate among patients who apparently carried wild-type $K I T$ could be the use of inadequate methods (e.g. Sanger sequencing) for the detection of the D816V KIT mutation, particularly in cases with low MC burden.

In turn, only 5/34 (15\%) adult mastocytosis patients who were not screened for the KIT mutation have been reported so far to respond to imatinib [31, 35, 63, 64]. Two of these patients only had transient improvement of symptoms [35], one had CM associated with HES and actually showed CR of HES with persistence of (cutaneous) mastocytosis lesions [31], one ASM patient with an associated eosinophilia and PDGFR $\beta$ gene rearrangement achieved CR [63], and the remaining patient showed PR consisting of $50 \%$ reduction of BM MC counts after therapy [64]. Following the same considerations as described above for the D816V-negative patients, the "true" response rate (e.g. as defined by $\geq 50 \%$ MC cytoreduction) among patients with unknown KIT mutational status and no imatinib-sensitive mutations involving other genes (e.g. PDGFR) would decrease to only $3 \%$ ( $1 / 34$ cases). Thereby, the estimated probability of lack of response to imatinib among patients who were not screened for KIT mutations is of $97 \%$, which correlates with the expected frequency of exon 17 KIT mutations $(\sim 94 \%)$ in SM, when highly-sensitive and robust PCRbased methods are used [4-7].

Although response to imatinib has been also reported in $13 / 28$ patients $(46 \%)$ with exon 17 KIT mutations $[38,39,45,50,51]$, most of such responses were purely symptomatic, a significant reduction (e.g. $\geq 50 \%$ ) in BM MC infiltration after therapy being documented in only 3 cases $(11 \%)[38,45]$. Of note, among all such cases, the only patient who showed CR presented with an associated imatinib-sensitive BCR/ABL-positive CML [38].

In summary, our observations together with previous data from the literature suggest that the efficacy of imatinib in terms of reducing MC tumor load in SM patients lacking the $\mathrm{D} 816 \mathrm{~V}$ KIT mutation, relies on the existence of imatinib-sensitive genetic defects such as extracellular membrane/transmembrane KIT mutations or $P D G F R$ gene rearrangements, rather than on the absence of the KIT D $816 \mathrm{~V}$ mutation by itself. Thus, the few responses reported in true D816V-negative patients who were only screened for mutations in exon 17 of the KIT gene, could be most likely related to the presence of already-known (unexplored) imatinib-sensitive $K I T$ and/or 
PDGFR mutations, or still undiscovered imatinib-sensitive mutations in genes other than KIT. Importantly, since objective responses to imatinib have also been obtained in ISM [14, 15, 18, 45, 54] SSM [45], MCL [15, 17] and SM-AHNMD [32, 34, 37, 38, 51, 62, 63], it seems reasonable that imatinib therapy should not be restricted to patients with ASM, whenever imatinib-sensitive molecular alterations are detected.

\section{MATERIALS AND METHODS}

\section{Inclusion and exclusion criteria}

The inclusion criteria used in this phase IV, open-label, uncontrolled clinical trial with imatinib (clinicaltrials.gov \#NCT01297777) were as follows: 1) age $\geq 18$ years; 2) diagnosis of systemic MC disease according to the WHO 2008 diagnostic criteria [1] and more recent criteria for WDSM [19], and; 3) absence of exon 17 KIT mutation. According to such criteria, all adult patients fulfilling the WHO 2008 diagnostic criteria for SM (with or without WSDM) and those who met the WDSM criteria (even when the WHO 2008 diagnostic criteria were not strictly fulfilled in the presence of a significant MC burden in $\geq$ two tissues), were eligible for participating in the study, independently from the type and severity of MC mediator-release symptoms and the levels of sT, whenever mutations at exon 17 of the KIT gene were ruled out. For the purposes of this study, patients within the ASM, MCL or SM-AHNMD disease categories according to the WHO 2008 classification of mastocytosis are also referred to as having advanced disease, as proposed elsewhere [41]; otherwise, patients were considered as having nonadvanced disease.

Additionally, the following exclusion criteria were used: 1) previous treatment with TKI; 2) serum positivity for the human immunodeficiency virus (HIV) or active viral hepatitis; 3) impaired liver function, defined as serum bilirubin levels $\geq 2 \mathrm{mg} / \mathrm{dL}$ and/or aspartate transaminase (AST) or alanine transaminase $($ ALT) $\geq 3$ times upper normal limit; 4) impaired renal function, defined as serum creatinine $\geq 2 \mathrm{mg} / \mathrm{dL} ; 5$ ) grade $\geq 3$ cytopenias not related to mastocytosis; 6) severe cardiopathy (grade III/IV of New York Heart Association -NYHA-, or left ventricular ejection fraction $<50 \%$ ); 7) pregnancy or breastfeeding, and; 8) female patients not using contraceptive methods.

\section{Patients}

Ten adult patients ( 2 males, 8 females) selected from a group of 453 consecutive SM patients followed at the Spanish Network on Mastocytosis (REMA) were enrolled in the study between January 2011 and August 2011. All patients were treated on an intention-to-cure basis, regardless of the prognostic impact of the specific subtype of mastocytosis or the severity of MC-mediator release- associated symptoms. Each patient gave his/her written informed consent to participate in the study, which was approved by the local institutional Ethics Committee (Complejo Hospitalario de Toledo, Toledo, Spain) where the trial took place.

\section{Screening for KIT mutations}

Absence of the D816V KIT mutation and other exon 17 KIT mutations was confirmed in genomic DNA extracted from fluorescence-activated cell sorting (FACS)purified BM MCs by a previously described peptide nucleic acid (PNA)-mediated polymerase chain reaction (PCR) technique [4]. Mutations involving other exons of $K I T$ were also investigated by direct sequencing of PCR products using the Sanger method [23], such mutations being detected in 4/10 cases.

\section{Treatment protocol and follow-up schedule}

Patients who showed >30\% BM MC infiltration by immunohistochemistry, advanced disease (defined by the presence of C-findings, $>20 \%$ of MCs in BM smears and/ or an associated non-MC lineage hematological disease) and/or another malignant mastocytosis-associated disease (e.g. GIST), received $400 \mathrm{mg} /$ day of imatinib orally for 12 months $(n=6 / 10)$; otherwise, a standard dose of $300 \mathrm{mg} /$ day was administered for 12 months $(n=4 / 10)$. Among those patients selected to receive $400 \mathrm{mg} /$ day of imatinib, treatment was discontinued whenever $<10 \%$ decrease in BM MC tumor load by flow cytometry had been achieved at month +6 of therapy. Potential treatment-related adverse events were closely monitored throughout the study and graded according to the National Cancer Institute Common Toxicity Criteria whenever they developed. In patients who had grade 3 or 4 adverse events, imatinib was either reduced by $100 \mathrm{mg}$ or transiently stopped until the adverse event had resolved and reintroduced afterward at lower doses, respectively.

Blood tests including complete blood count and differential, routine biochemistry and sT were systematically performed before starting imatinib and at months $+1,+2,+3,+6,+9$ and +12 of therapy. Spleen and liver ultrasonography was performed in all cases before starting imatinib and, whenever organomegalies were detected, also at months +6 and +12 of therapy.

Both clinical evaluation and physical examination of patients were carried out by specialized medical doctors with expertise on mastocytosis (I.A-T, A.M and/ or L.E) at months $+3,+6,+9$ and +12 . Mastocytosisrelated symptoms were evaluated in every patient by the same doctors using Likert-type scales obtained from specific questionnaires designed by the REMA, by which MC-mediator release-associated symptoms (e.g. pruritus, flushing, abdominal cramping, diarrhea and anaphylaxis) were individually graded according to their frequency 
$(0=$ absent; $1=$ less than monthly; $2=$ monthly; $3=$ weekly; 4 = daily or almost daily) and degree of severity $(1=$ no therapy required; $2=$ kept under control with antiH1; $3=$ corticosteroids required; $4=$ epinephrine and or hospitalization required). Individual scores per symptom were calculated for the 3 months preceding the start of imatinib, and then at months $+3,+6,+9$ and +12 of therapy, by multiplying their frequency and severity values (Figure 3 ).

To evaluate the cutaneous response, skin biopsies were performed before starting imatinib and at months +6 and +12 of therapy in all patients who presented with mastocytosis in the skin. To evaluate changes in BM MC infiltration, a complete BM study including histology, cytology and flow cytometry, was performed before starting imatinib and at month +12 of therapy; an additional BM study was performed at month +6 of therapy in those patients who had > 30\% BM MC infiltration and/or advanced disease at the moment of starting therapy. For both cytologic and histologic studies, all specimens were independently reviewed by three experts (I.A-T, L.E and M.M). For the evaluation of MCs by flow cytometry, all BM samples were analyzed in parallel in two different laboratories of the REMA by two and three independent experts, respectively (JM.M and L.S-M, and A.M, C.C and C.T, respectively).

\section{Endpoints and response criteria}

The primary and secondary endpoints of the study were: 1) a change (e.g. decrease) in MC infiltration of involved organs including the BM and the skin, 2) a change (e.g. decrease) in the size of organomegalies (if present) as evaluated by abdominal ultrasonography, and 3) a change (e.g. decrease) in MC-mediator releaseassociated symptoms and sT levels. Complete response (CR) was defined as complete resolution of all disease signs and symptoms including BM MC infiltration, skin lesions, organomegalies and MC-mediator releaseassociated symptoms, plus a decrease in sT below normal values $(<11.5 \mu \mathrm{g} / \mathrm{L})$. In turn, partial response (PR) was defined as $\geq 50 \%$ reduction in $\mathrm{BM} \mathrm{MC}$ infiltration and improvement of skin lesions and/or organomegalies. All other patients were considered as non-responders (NR). Patients having outcomes other than $\mathrm{CR}$, symptomatic response was evaluated as a separate endpoint using Likert-type scales obtained from specific questionnaires designed by the REMA.

All authors had access to clinical trial data and participated in data analysis, interpretation of results and writing, revision and final approval of the manuscript.

\section{Abbreviations}

ALT: Alanine Transaminase; ASM: Aggressive systemic mastocytosis; AST: Aspartate Transaminase;
BM: Bone marrow; CEL: Chronic eosinophilic leukemia, CM: Cutaneous mastocytosis; CML: Chronic myeloid leukemia; CR: Complete response; DNA: Deoxyribonucleic acid; ECNM: European Competence Network on Mastocytosis; FACS: Fluorescence-activated cell sorting; FDA: Food and Drug Administration; FGFR1: Fibroblast Growth Factor Receptor 1; G-CSF: Granulocyte colony-stimulating factor; GIST: Gastrointestinal stromal tumor; HES: Hypereosinophilic syndrome; HIV: Human Immunodeficiency Virus; HUMARA: Human androgen receptor assay; ISM: Indolent systemic mastocytosis; IWG-MRT: International Working Group on Myeloproliferative Neoplasms Research and Treatment; JAK: Janus kinase; MC: Mast cell; MCL: Mast cell leukemia; NR: No response; NYHA: New York Heart Association; PB: Peripheral blood; PCR: Polymerase chain reaction; PDGFR: Platelet-derived growth factor receptor; PNA: Peptide nucleic acid; PR: Partial response; REMA: Spanish Network on Mastocytosis; SM: Systemic mastocytosis; SM-AHNMD: Systemic mastocytosis with an associated clonal haematological non-mast cell disease; SSM: Smoldering systemic mastocytosis; sT: Serum tryptase; TK: Tyrosine kinase; TKI: Tyrosine kinase inhibitor; WDSM: Well-differentiated systemic mastocytosis; WHO: World Health Organization.

\section{CONFLICTS OF INTEREST}

The authors declare no competing financial interest.

\section{GRANT SUPPORT}

This work was supported by grants from the Ministry of Health, Social Services and Equality, Madrid, Spain (grant EC11-287) (L.S-M), Fundación Mutua Madrileña (Madrid, Spain), Asociación Española de Enfermos de Mastocitosis (Madrid, Spain), Fundación Ramón Areces, Madrid, Spain (grant CIVP16A1806), Red Temática de Investigación Cooperativa en Cancer -RTICC- of the Instituto de Salud Carlos III, Ministry of Economy and Competitivity, Madrid, Spain (grant RD12/0036/0048, FEDER) and Fundación Samuel Solorzano, Salamanca, Spain (grant FS/22-2014).

\section{REFERENCES}

1. Horny HP, Metcalfe DD, Bennet JM, Bain BJ, Akin C, Escribano L, Valent P, Swerdlow SH, Campo E, Harris NL, Jaffe ES, Pileri SA, Stein H, et al. Mastocytosis. In: Swerdlow $\mathrm{SH}$, et al. WHO classification of tumours of haematopoietic and lymphoid tissues. Lyon: IARC. 2008; 54-63.

2. Escribano L, Orfao A, Villarrubia J, Díaz-Agustin B, Cerveró C, Ríos A, Velasco JL, Ciudad J, Navarro JL, San Miguel JF. Immunophenotypic characterization of human bone marrow mast cells. A flow cytometric study of normal 
and pathological bone marrow samples. An Cell Pathol. 1998; 16:151-159.

3. Escribano L, Díaz Agustín B, Bravo P, Navalón R, Almeida J, Orfao A. Immunophenotype of Bone Marrow Mast Cells in Indolent Systemic Mast Cell Disease in Adults. Leuk Lymphoma. 1999; 35:227-235.

4. Garcia-Montero AC, Jara-Acevedo M, Teodosio C, Sanchez ML, Nunez R, Prados A, Aldanondo I, Sanchez L, Dominguez M, Botana LM, Sanchez-Jimenez F, Sotlar K, Almeida J, et al. KIT mutation in mast cells and other bone marrow haematopoietic cell lineages in systemic mast cell disorders. A prospective study of the Spanish Network on Mastocytosis (REMA) in a series of 113 patients. Blood. 2006; 108:2366-2372.

5. Kristensen T, Vestergaard H, Bindslev-Jensen C, Møller M, Broesby-Olsen S. Sensitive KIT D816V mutation analysis of blood as a diagnostic test in mastocytosis. Am J Hematol. 2014; 89:493-498.

6. Jara-Acevedo M, Teodosio C, Sanchez-Munoz L, AlvarezTwose I, Mayado A, Caldas C, Matito A, Morgado JM, Muñoz-Gonzalez JI, Escribano L, Garcia-Montero A, Orfao A. Detection of the KIT D816V mutation in peripheral blood of systemic mastocytosis: diagnostic implications. Mod Pathol. 2015; 28:1138-1149.

7. De Matteis G, Zanotti R, Colarossi S, De Benedittis C, GarciaMontero A, Bonifacio M, Sartori M, Aprili F, Caruso B, Paviati E, Carli G, Perbellini O, Zamò A, et al. The impact of sensitive KIT D816V detection on recognition of indolent Systemic Mastocytosis. Leuk Res. 2015; 39:273-278.

8. Longley BJ, Reguera MJ, Ma Y. Classes of c-KIT activating mutations: proposed mechanisms of action and implications for disease classification and therapy. Leuk Res. 2001; 25:571-576.

9. Furitsu T, Tsujimura $\mathrm{T}$, Tono $\mathrm{T}$, Ikeda H, Kitayama $\mathrm{H}$, Koshimizu U, Sugahara H, Butterfield JH, Ashman LK, Kanayama Y Matsuzawa Y, Kitamura Y, Kanakura Y. Identification of mutations in the coding sequence of the proto-oncogene c-kit in a human mast cell leukemia cell line causing ligand-independent activation of c-kit product. J Clin Invest. 1993; 92:1736-1744.

10. Akin C, Fumo G, Yavuz AS, Lipsky PE, Neckers L, Metcalfe DD. A novel form of mastocytosis associated with a transmembrane c-kit mutation and response to imatinib. Blood. 2004; 103:3222-3225.

11. Hartmann K, Wardelmann E, Ma YS, Merkelbach-Bruse S, Preussner LM, Woolery C, Baldus SE, Heinicke T, Thiele J, Buettner R, Longley BJ. Novel germline mutation of KIT associated with familial gastrointestinal stromal tumors and mastocytosis. Gastroenterology. 2005; 129:1042-1046.

12. Zhang LY, Smith ML, Schultheis B, Fitzgibbon J, Lister TA, Melo JV, Cross NC, Cavenagh JD. A novel K5091 mutation of KIT identified in familial mastocytosis - in vitro and in vivo responsiveness to imatinib therapy. Leuk Res. 2006; 30:373-378.

13. Nakagomi N, Hirota S. Juxtamembrane-type c-kit gene mutation found in aggressive systemic mastocytosis induces imatinib-resistant constitutive KIT activation. Lab Invest. 2007; 87:365-371.

14. Chan EC, Bai Y, Kirshenbaum AS, Fischer ER, Simakova O, Bandara G, Scott LM, Wisch LB, Cantave D, Carter MC, Lewis JC, Noel P, Maric I, et al. Mastocytosis associated with a rare germline KIT K509I mutation displays a welldifferentiated mast cell phenotype. J Allergy Clin Immunol. 2014; 134:178-187.

15. de Melo Campos P, Machado-Neto JA, Scopim-Ribeiro R, Visconte V, Tabarroki A, Duarte AS, Barra FF, Vassalo J, Rogers HJ, Lorand-Metze I, Tiu RV, Costa FF, Olalla Saad ST, et al. Familial systemic mastocytosis with germline KIT K509I mutation is sensitive to treatment with imatinib, dasatinib and PKC412. Leuk Res. 2014; 38:1245-1251.

16. Speight RA, Nicolle A, Needham SJ, Verrill MW, Bryon J, Panter S. Rare, germline mutation of KIT with imatinibresistant multiple GI stromal tumors and mastocytosis. J Clin Oncol. 2013; 31:e245-e247.

17. Mital A, Piskorz A, Lewandowski K, Wasag B, Limon J, Hellmann A. A case of mast cell leukaemia with exon 9 KIT mutation and good response to imatinib. Eur J Haematol. 2011; 86:531-535.

18. Alvarez-Twose I, Gonzalez P, Morgado JM, JaraAcevedo M, Sanchez-Munoz L, Matito A Mollejo M, Orfao A, Escribano L. Complete Response After Imatinib Mesylate Therapy in a Patient With Well-Differentiated Systemic Mastocytosis. J Clin Oncol. 2012; 30:e126-129.

19. Alvarez-Twose I, Jara-Acevedo M, Morgado JM, GarcíaMontero A, Sánchez-Muñoz L, Teodósio C Matito A, Mayado A, Caldas C, Mollejo M, Orfao A, Escribano L. Clinical, immunophenotypic, and molecular characteristics of well-differentiated systemic mastocytosis. J Allergy Clin Immunol. 2016; 137:168-178.

20. Druker BJ, Talpaz M, Resta DJ, Peng B, Buchdunger E, Ford JM, Lydon NB, Kantarjian H, Capdeville R, OhnoJones S, Sawyers CL.. Efficacy and safety of a specific inhibitor of the BCR-ABL tyrosine kinase in chronic myeloid leukemia. N Engl J Med. 2001; 344:1031-1037.

21. Demetri GD, von Mehren M, Blanke CD, Van den Abbeele AD, Eisenberg B, Roberts PJ, Heinrich MC, Tuveson DA, Singer S, Janicek M, Fletcher JA, Silverman SG, Silberman SL, et al. Efficacy and safety of imatinib mesylate in advanced gastrointestinal stromal tumors. N Engl J Med. 2002; 347:472-480.

22. Cortes J, Ault P, Koller C, Thomas D, Ferrajoli A, Wierda W, Rios MB, Letvak L, Kaled ES, Kantarjian H. Efficacy of imatinib mesylate in the treatment of idiopathic hypereosinophilic syndrome. Blood. 2003; 101:4714-4716.

23. Sanger F, Coulson AR. A rapid method for determining sequences in DNA by primed synthesis with DNA polymerase. J Mol Biol. 1995; 94:441-448.

24. Hartmann K, Escribano L, Grattan C, Brockow K, Carter MC, Alvarez-Twose I, Matito A, Broesby-Olsen S, Siebenhaar F, Lange M, Niedoszytko M, Castells M, Oude Elberink JN, et al. Cutaneous manifestations in 
patients with mastocytosis: Consensus report of the European Competence Network on Mastocytosis; the American Academy of Allergy, Asthma \& Immunology; and the European Academy of Allergology and Clinical Immunology. J Allergy Clin Immunol. 2016; 137:35-45.

25. Hauswirth AW, Simonitsch-Klupp I, Uffmann M, Koller E, Sperr WR, Lechner K, Valent P. Response to therapy with interferon alpha- $2 \mathrm{~b}$ and prednisolone in aggressive systemic mastocytosis: report of five cases and review of the literature. Leuk Res. 2004; 28:249-257.

26. Barete S, Lortholary O, Damaj G, Hirsch I, Chandesris MO, Elie C, Hamidou M, Durieu I, Suarez F, Grosbois B, Limal N, Gyan E, Larroche C, et al. Long-term efficacy and safety of cladribine (2-CdA) in adult patients with mastocytosis. Blood. 2015; 126:1009-1016.

27. Frost MJ, Ferrao PT, Hughes TP, Ashman LK. Juxtamembrane mutant V560GKit is more sensitive to Imatinib (STI571) compared with wild-type c-kit whereas the kinase domain mutant D816VKit is resistant. Mol Cancer Ther. 2002; 1:1115-1124.

28. Akin C, Brockow K, D'Ambrosio C, Kirshenbaum AS, Ma Y, Longley BJ and Metcalfe DD. Effects of tyrosine kinase inhibitor STI571 on human mast cells bearing wildtype or mutated c-kit. Exp Hematol. 2003; 31:686-692.

29. Ma YS, Zeng S, Metcalfe DD, Akin C, Dimitrijevic S, Butterfield JH, McMahon G, Longley BJ. The c-KIT mutation causing human mastocytosis is resistant to STI571 and other KIT kinase inhibitors; kinases with enzymatic site mutations show different inhibitor sensitivity profiles than wild-type kinases and those with regulatory-type mutations. Blood. 2009; 99:1741-1744.

30. Laine E, Chauvot de Beauchêne I, Perahia D, Auclair C, Tchertanov L. Mutation D816V alters the internal structure and dynamics of c-KIT receptor cytoplasmic region: implications for dimerization and activation mechanisms. PLoS Comput Biol. 2011; 7:e1002068.

31. Pottier P, Planchon B, Grossi O. Complete remission with imatinib mesylate (Glivec) of an idiopathic hypereosinophilic syndrome associated with a cutaneous mastocytosis after failure of interferon-alpha. Rev Med Interne. 2003; 24:542-546.

32. Pardanani A, Elliott M, Reeder T, Li CY, Baxter EJ, Cross NC, Tefferi A. Imatinib for systemic mast-cell disease. Lancet. 2003; 362:535-537.

33. Pardanani A, Ketterling RP, Brockman SR, Flynn HC, Paternoster SF, Shearer BM, Reeder TL, Li CY, Cross NC, Cools J, Gilliland DG, Dewald GW, Tefferi A. CHIC2 deletion, a surrogate for FIP1L1-PDGFRA fusion, occurs in systemic mastocytosis associated with eosinophilia and predicts response to imatinib mesylate therapy. Blood. 2003; 102:3093-3096.

34. Elliott MA, Pardanani A, Li CY, Tefferi A. Immunophenotypic normalization of aberrant mast cells accompanies histological remission in imatinib-treated patients with eosinophilia-associated mastocytosis. Leukemia. 2004; 18:1027-1029.

35. Hennessy B, Giles F, Cortes J, O'brien S, Ferrajoli A, Ossa G, Garcia-Manero G, Faderl S, Kantarjian H, Verstovsek S. Management of patients with systemic mastocytosis: Review of M. D. Anderson cancer center experience. Am J Hematol. 2004; 77:209-214.

36. Musto P, Falcone A, Sanpaolo G, Bodenizza C, Carella AM. Inefficacy of imatinib-mesylate in sporadic, aggressive systemic mastocytosis. Leuk Res. 2004; 28:421-422.

37. Pardanani A, Brockman SR, Paternoster SF, Flynn HC, Ketterling RP, Lasho TL, Ho CL, Li CY, Dewald GW, Tefferi A. FIP1L1-PDGFRA fusion: Prevalence and clinicopathologic correlates in 89 consecutive patients with moderate to severe eosinophilia. Blood. 2004; 104:30383045 .

38. Agis H, Sotlar K, Valent P, Horny HP. Ph-Chromosomepositive chronic myeloid leukemia with associated bone marrow mastocytosis. Leuk Res. 2005; 29:1227-1232.

39. Heinrich MC, Joensuu H, Demetri GD, Corless CL, Apperley J, Fletcher JA, Soulieres D, Dirnhofer S, Harlow A, Town A, McKinley A, Supple SG, Seymour J, et al. Phase II, Open-Label Study Evaluating the Activity of Imatinib in Treating Life-Threatening Malignancies Known to Be Associated with Imatinib-Sensitive Tyrosine Kinases. Clin Cancer Res. 2008; 14:2717-2725.

40. Valent P, Akin C, Escribano L, Fodinger M, Hartmann K, Brockow K, Castells M, Sperr WR, Kluin-Nelemans HC, Hamdy NA, Lortholary O, Robyn J, van Doormaal J, et al. Standards and standardization in mastocytosis: consensus statements on diagnostics, treatment recommendations and response criteria. Eur J Clin Invest. 2007; 37:435-453.

41. Gotlib J, Pardanani A, Akin C, Reiter A, George T, hermine O, Kluin-Nelemans H, Hartmann K, Sperr WR, Brockow K, Schwartz LB, Orfao A, Deangelo DJ, et al. International Working Group-Myeloproliferative Neoplasms Research and Treatment (IWG-MRT) \& European Competence Network on Mastocytosis (ECNM) consensus response criteria in advanced systemic mastocytosis. Blood. 2013; 121:2393-2401.

42. Ryan RJ, Akin C, Castells M, Wills M, Selig MK, Nielsen GP, Ferry JA, Hornick JL. Mast cell sarcoma: a rare and potentially under-recognized diagnostic entity with specific therapeutic implications. Mod Pathol. 2013; 26:533-543.

43. Morren MA, Hoppe A, Renard M, Debiec Rychter M, Uyttebroeck A, Dubreuil P, Martin L. Imatinib mesylate in the treatment of diffuse cutaneous mastocytosis. J Pediatr. 2013; 162:205-207.

44. Hoffmann KM, Moser A, Lohse P, Winkler A, Binder B, Sovinz P, Lackner H, Schwinger W, Benesch M, Urban C. Successful treatment of progressive cutaneous mastocytosis with imatinib in a 2-year-old boy carrying a somatic KIT mutation. Blood. 2008; 112:1655-1657. 
45. Droogendijk HJ, Kluin-Nelemans HJ, Van Doormaal JJ, Oranje AP, van de Loosdrecht AA, van Daele PL. Imatinib mesylate in the treatment of systemic mastocytosis: a phase II trial. Cancer. 2006; 107:345-351.

46. Florian S, Esterbauer H, Binder T, Müllauer L, Haas OA, Sperr WR, Sillaber C, Valent P. Systemic mastocytosis (SM) associated with chronic eosinophilic leukemia (SMCEL): detection of FIP1L1/PDGFRalpha, classification by WHO criteria, and response to therapy with imatinib. Leuk Res. 2006; 30:1201-1205.

47. Merante S, Chichino G, Boveri E, Gottardi E, Soverini S, Cilloni D, Martinelli G. First case of an AIDS patient with systemic mast cell disease associated with FIP1-positive eosinophilia treated with imatinib mesylate therapy. J Clin Oncol. 2006; 24:e6-e7.

48. Koenig M, Morel J, Reynaud J, Varvat C, Cathebras P. An unusual cause of spontaneous bleeding in the intensive care unit - mastocytosis: a case report. Cases J. 2008; 1:100.

49. Pagano L, Valentini CG, Caira M, Rondoni M, Van Lint MT, Candoni A, Allione B, Cattaneo C, Marbello L, Caramatti C, Pogliani EM, Iannitto E, Giona F, et al. Advanced mast cell disease: an Italian Hematological Multicenter experience. Int J Hematol. 2008; 88:483-488.

50. Valentini CG, Rondoni M, Pogliani EM, Van Lint MT, Cattaneo C, Marbello L, Pulsoni A, Giona F, Martinelli G, Leone G, Pagano L. Mast cell leukemia: a report of ten cases. Ann Hematol. 2008; 87:505-508.

51. Vega-Ruiz A, Cortes JE, Sever M, Manshouri T, QuintásCardama A, Luthra R, Kantarjian HM, Verstovsek S. Phase II study of imatinib mesylate as therapy for patients with systemic mastocytosis. Leuk Res. 2009; 33:1481-1484.

52. Jung AG, Horny HP, Sotlar K, Overbeck T, Schön MP, Lippert U. Imatinib mesylate for aggressive systemic mastocytosis with long bone osteolysis. J Am Acad Dermatol. 2011; 65:224-226.

53. Ma HB, Xu X, Liu WP, Chang H, Zeng F, Wang YC. Successful treatment of mast cell sarcoma of the uterus with imatinib. Int J Hematol. 2011; 94:491-494.

54. Agarwala MK, George R, Mathews V, Balasubramanian P, Thomas M, Nair S. Role of imatinib in the treatment of pediatric onset indolent systemic mastocytosis: a case report. J Dermatolog Treat. 2013; 24:481-483.

55. Vannorsdall EJ, Collins JA, Chen QC, Sarai G, Baer MR. Symptomatic response to imatinib mesylate in cutaneous mastocytosis associated with chronic myelomonocytic leukemia. Curr Oncol. 2013; 20:e349-e353.

56. Valent P, Cerny-Reiterer S, Hoermann G, Sperr WR, Müllauer L, Mannhalter C, Pehamberger H. Long-lasting complete response to imatinib in a patient with systemic mastocytosis exhibiting wild type KIT. Am J Blood Res. 2014; 4:93-100.

57. Marton I, Posfai E, Borbenyi Z, Bödör C, Papp G, Demeter J, Korom I, Varga E, Bata-Csörgő Z, et al. Therapeutic challenge during the long-term follow-up of a patient with indolent systemic mastocytosis with extensive cutaneous involvement. Eur Rev Med Pharmacol Sci. 2015; 19:1607-1609.

58. Auquit-Auckbur I, Lazar C, Deneuve S, Guillemet C, Cordel N, Blanchard F, Joly P, Courville P. Malignant transformation of mastocytoma developed on skin mastocytosis into cutaneous mast cell sarcoma. Am J Surg Pathol. 2012; 36:779-782.

59. Sakane-Ishikawa E, Kodaka T, Tsunemine H, Itoh K, Akasaka H, Kusama T, Imaizumi K, Taketomi M, Sada A, Katayama Y, Itoh T, Takahashi T. Eosinophilia and bone lesion as clinical manifestations of aggressive systemic mastocytosis. J Clin Exp Hematop. 2013; 53:207-213.

60. Iliakis T, Rougkala N, Diamantopoulos PT, Papadopoulou V, Kalala F, Zervakis K, Giannakopoulou N, Chatzinikolaou P, Levidou G, Lakiotaki E, Korkolopoulou P, Patsouris E, Variami E, et al. An adult patient with systemic mastocytosis and B-acute lymphoblastic leukemia. Case Rep Med. 2014; 2014:526129.

61. Savini P, Rondoni M, Poletti G, Lanzi A, Quercia O, Soverini S, De Benedittis C, Musardo G, Martinelli G, Stefanini GF. Serum total tryptase level confirms itself as a more reliable marker of mast cells burden in mast cell leukaemia (aleukaemic variant). Case Rep Hematol. 2015; 2015:737302.

62. Lahortiga I, Akin C, Cools J, Wilson TM, Mentens N, Arthur DC, Maric I, Noel P, Kocabas C, Marynen P, Lessin LS, Wlodarska I, Robyn J, et al. Activity of imatinib in systemic mastocytosis with chronic basophilic leukemia and a PRKG2-PDGFRB fusion. Haematologica. 2008; 93:49-56.

63. Dalal BI, Horsman DE, Bruyere H, Forrest DL. Imatinib mesylate responsiveness in aggressive systemic mastocytosis: Novel association with a platelet derived growth factor receptor beta mutation. Am J Hematol. 2007; 82:77-79.

64. Gollard RP, Ruemmler-Fish C, Garcia D. Systemic Mastocytosis: documented pathologic response to imatinib. Eur J Haematol. 2007; 79:367-368.

65. Kupfer SS, Hart J, Mohanty SR. Aggressive systemic mastocytosis presenting with hepatic cholestasis.. Eur J Gastroenterol Hepatol. 2007; 19:901-905.

66. Yoshida C, Takeuchi M, Tsuchiyama J, Sadahira Y. Successful treatment of KIT D816V-positive, imatinibresistant systemic mastocytosis with interferon-alpha. Intern Med. 2009; 48:1973-1978.

67. Moore AE, Johnston WH, Hever A, Peng S, Kujubu DA. Systemic mastocytosis presenting with acute oliguric renal failure: report of a case and review of the literature. Int Urol Nephrol. 2012; 44:639-642. 